\title{
FORMULATION OF COMPOSITE FLOUR MIXTURE FOR BREAD AND FLAT BREAD PRODUCTS
}

By

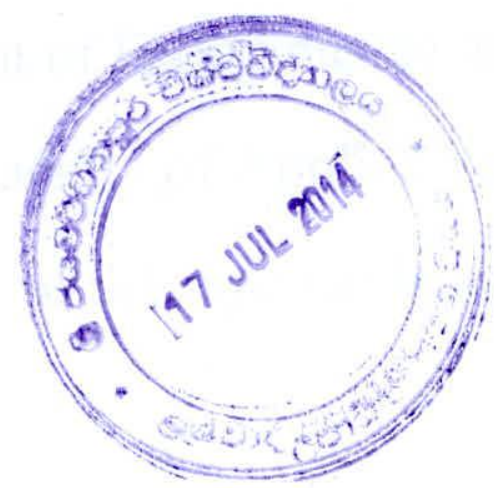

MSc 
"I certify that the above statement made by the candidate is true and that this thesis is suitable for submission to the university for the purpose of evaluation"

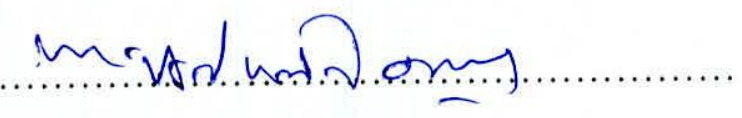

Dr. (Mr.) Jagath Wansapala

Date

Department of Food Science and Technology,

Faculty of Applied Sciences,

University of Sri Jayewardenepura,

Sri Lanka. 


\section{Dedicated to my loving family members}




\section{Table of Contents}

\section{Page No}

List of Contents

$\mathrm{i}$

List of table

v

List of figures vi

Acknowledgement vii

Abstract viii

\section{Chapter 01}

Introduction

1.1 Major objectives $\quad 2$

1. 2 Minor objective 2

\section{Chapter 02}

2 Review of Literature 3

2.1 Background 3

2. 2 History of Composite Flour 4

2.3 Wheat Flour 6

2. 3.1 Taxonomy and Classification of Wheat 7

2.3. 2 Parts of Wheat Grain 8

2.3.3 Nutrition values of Processed Wheat Flour 9

2.3.4 Atta Flour Preparation 9

2.3.5 Nutrition values of Atta flour $\quad 10$

2.4 Rice Flour $\quad 11$

2.4.1 Taxonomy and Classification of Rice 12 
2.4. 2 Parts of Rice grain

2.4.3 Rice Flour Preparation

2.4.4 Nutrition Status of Rice

2. 5 Green Gram flour

2. 5.1 Taxonomy and Classification of Green Gram

2.5.2 Parts of Green Gram Seeds

2.5.3 Green Gram Flour Preparation

2.5.4 Nutrition values of Green Gram Flour

2.6 Leavened Breads

2.7 Dough Development and Fermentation

2.7.1 Dough Mixing

2.7.2 Dough Fermentation 25

2.7.3 Chemistry of Dough Development

2.7.4 Dough Processing

2.8 Baking

2.9 Other Ingredients for Bread Preparation 30

2.10 Bread Quality Assessment

2.11 Flat Breads

2.12 Functional Properties and Anti-Nutritional Factors

\section{Chapter 03}

3. Methodology

3.1 Materials Used for Composite Flour Mixture

3.1.1 Preparation of Rice Flour

3.1.2 Preparation of Atta Flour

3.1.3 Preparation of Green Gram Flour

3.1.4 Preparation of Wheat Flour 
3.2.1 Formulation of Bakery Products $\quad 39$

3.2.1.1 Process Flow Chart for Bread Preparation $\quad 40$

3.2.2 Quality Testing of Bread Product 43

3.2.3 Preparation of Flat Bread Products 43

3.2.3.1 Preparation of Roti 44

3.2.3.2 Preparation of Pittu $\quad 45$

3.2.3.3 Preparation of Hopper $\quad 48$

3.3 Sensory Evaluation $\quad 49$

3.4 Selections of Best Formula $\quad 49$

3.5 Chemical Analysis $\quad 50$

3.5.1 Determination of Moisture Content 50

3.5.2 Determination of Total Fat-(Solvent Extraction Method) 51

3.5.3 Determination of Crude Protein 52

3.5.4 Determination of Fibre 55

3.5.5 Determination of Ash $\quad 57$

3.5.6 Determination of Acid Insoluble Ash $\quad 59$

3.6 Determination of Nutrients by Atomic Absorption Method 59

3.7 Microbiological Analysis $\quad 60$

3.7.1 Total Plate Count 60

3.7.2 Enumeration of Yeast and Mold 61

3.8 Packaging of Flour for Shelf life Determination $\quad 61$

\section{Chapter 04}

4. Results and Discussion 63

4.1 Sensory Evaluations 63

4.2 Results of Quality Testing 63

4.3 Chemical Analysis Results of Flour 64 
4.3.2 Total Fat Content of Flour $\quad 65$

4.3.3 Crude Protein Content of Flour 65

4.3.4 Crude Fibre Content of Flour 65

4.3.5 Ash Content of Flour 66

4.4 Microbiology Results of Flour $\quad 67$

$\begin{array}{ll}\text { 4.4.1Total Plate Count } & 67\end{array}$

4.4.2 Yeast and Mold $\quad 67$

\section{Chapter 05}

5 Conclusions 68

\section{Chapter 06}

6 Recommendations for Further Improvements 69

$\begin{array}{ll}\text { References } & 70\end{array}$

Appendix

Appendix 1 Sensory ballot paper $\quad 72$

$\begin{array}{ll}\text { Appendix } 2 \text { Product samples } & 73\end{array}$

$\begin{array}{ll}\text { Appendix } 3 \text { Kruskal -Wallis Test } & 75\end{array}$ 


\section{List of figures}

Figure 2.1 Mature Seeds of Triticum aestivum 7

Figure 2.2 Structure of Wheat Seeds 8

$\begin{array}{ll}\text { Figure 2.3 Oryza sativa - rice } & 12\end{array}$

Figure 2.4 Oryza sativa - rice Parts of whole grain 13

$\begin{array}{ll}\text { Figure } 2.5 \text { Seeds of V. radiate } & 16\end{array}$

Figure 2.6 800px-Hammer mill open front 18

Figure 2.7 Whole Wheat Bread 22

Figure 2.8 Typical Baking Curves $\quad 29$

Figure 3.1 Process Flow of Green Gram Flour Preparation 38

Figure 3.2 Bread Production 41

Figure 3.3 Process Steps of Rotti Production 44

Figure 3.4 Process Steps of Pittu Production 46

Figure 3.5 Process Steps of Hopper Production 48

Figure 4.1 Sensory Evaluation Chart 63

Figure i Hopper Sample $\quad 73$

$\begin{array}{ll}\text { Figure ii Pittu Sample } & 73\end{array}$

$\begin{array}{ll}\text { Figure iii Bread Sample } & 74\end{array}$

Figure iv Rotti Sample $\quad 74$

Figure 4.5 Sensory Evaluation Chart $\quad 75$ 


\section{Acknowledgement}

I wish to express sincere thanks for the valuable guidance and encouragement given to me through this project by my supervisor Dr.Jagath Wansapala is gratefully acknowledged of Department of Food science, University of Sri Jayewardenepura.

I am greatly indebted to my family members for the immense support given to me during this study. A special thanks to all members of academic staff of Department of Food science and Technology University of Sri Jayewardenepura for their commitments and

Finally word of thanks to all the laboratory staff of Department of Food science and Technology University of Sri Jayewardenepura for the kind assistant during the research period. 


\section{Chapter 01}

\section{Introduction}

Wheat (Triticum aestivum) is the major food product among all cereal crops. It is a staple food of large segment of world population. Wheat flour is most commonly used type of flour in the bakery industry. This is mainly due to its high molding ability which is given by the high content of gluten. Wheat flour has glutenin and gliadin proteins. When stir together flour and water, two proteins in the flour glutenin and gliadin grab water and each other to form an elastic mass of molecules that call as gluten. Bread can only be made from imported high gluten wheat which is not suitable for cultivation in the tropical areas for climatic reasons (Edema et al., 2005). Several developing countries have encouraged the initiation of programs to evaluate the feasibility of alternative locally available flours as a substitute for wheat flour. Many efforts have been carried out to promote the use of composite flours, in which a portion of wheat flour is replaced by locally grown crops, to be used in bread, thus decreasing the cost associated with imported wheat (Olaoye et al., 2006). Refined grains flour used to make white bread have had the fiber-dense bran and the nutrient-rich germ processed out, leaving only the starchy endosperm. This means that refined grain is not as rich in essential fatty acids, vitamin E, magnesium, and zinc. Some flour and bread manufacturers "enrich" their bread by adding extra vitamins back in. But it's still better to eat whole grains.

The World Bank last year also reported that during the past 50 years, According to the health ministry's Non-Communicable Disease Unit, around 350 Sri Lankans die daily, due to heart attacks, diabetes mellitus, hypertension, and kidney and respiratory deaths due to heart disease in Sri Lanka have risen from $3 \%$ to $24 \%$, while the percentage of deaths due to infectious disease dropped from $24 \%$ to $12 \%$.Health Ministry found that the rise in non-communicable diseases was mainly due to changes in lifestyle, unhealthy food patterns, tobacco use and alcohol consumption as well as physical inactivity. Food is played a major roll for increasing trend of non-communicable disease. Healthy foods becoming very popular among the aged population and there is an emerging market for healthy, balanced food due to high trend of non-communicable disease in our society Addition of legume and beans to cereal based products could be a good option for increasing the intake of legumes and beans. In addition, legume proteins are rich in lysine and deficient in sulphur containing amino acids, whereas cereal proteins are deficient in lysine, but have adequate amounts of sulphur amino acids. Therefore, the combination of grain with legume proteins would provide better overall essential amino acid balance, helping to overcome the local protein calorie malnutrition problem. In addition to this, Sri Lankan population is facing a mineral deficiency too, especially Iron. The composite flour mixture consists of Atta flour, Green gram (Vigna radiate)), Rice (Oryza sativa) and Wheat flour are the raw materials used to prepare bread. The flour mixture can be used as multipurpose approach, production of all the bakery products and flat breads such as Pittu, Rotty and Hoppers with nutritionally balanced, high amount of minerals and fibers rich. This may be helped to regulate blood sugar as well as other health benefits too. (Abdel-Aal, E.S., F.W. Sosulski, M.M. Yousef and A.A. Shehata, 1993.) 
Sri Lanka is blessed with wide variety of cereals; Rice is staple food in Sri Lanka and several other Asian countries Green gram also successfully grown in the country. There for by introducing such formula we can encourage and eye open the society. In this study, overall bread quality at the different levels of whole flours substitution levels was found to be acceptable. However, acceptability increased as the level of whole grains, decreased.

Higher levels of substitution for wheat flour with whole flour mixtures resulted in lower circumferences of Bread and a decrease in specific volume of pan bread. However, crumb colour was directly related to the level of substitution. Increasing the level of whole flours decreased cohesiveness, springiness and resilience, and increased hardness, gumminess and chewiness of pan bread made with whole or wheat composite flour. Acceptable pan and Balady bread could be made by substitute with up to $90 \%$ whole flours. However, sensory evaluation results also not indicated significant preference for bread that had $90 \%$ whole flour with control.

Since Wheat flour products plays very big role in our society and customer expectations are more towards to health benefited foods. There for it becomes a nutritious balanced food product utmost suitable for modern society.

The objective of this study was to evaluate the physio Chemical and baking properties of composite flours as well as to determine the organoleptic acceptability of the resulting breads.

\subsection{Major Objective}

- Development of a composite flour mixture that can be used for multipurpose food preparations.

\subsection{Minor Objectives}

- Determination of chemical composition.

- Evaluation of microbiological safety in composite flour.

- Determination Shelf life of flour mixture.

- Value addition to locally available ingredients.

- Introduction of products which is affordable to wide range of consumer class.

- Provision to diminish micro nutrition in the country. 


\section{Chapter 02}

\section{Review of Literature}

\subsection{Background}

The history of bread is goes back at least 30,000 years. The first bread produced was probably cooked versions of a grain-paste, made from roasted and ground cereal grains and water, and may have been developed by accidental cooking or deliberate experimentation with water and grain flour. Flat bread of these types also formed a staple in the diet of many early civilizations with the Sumerians eating a type of barley flat cake, and the 12th century BC Egyptians being able to purchase flat bread called ta from stalls in the village streets.

The earliest archaeological evidence for flour, which was likely processed into unleavened bread, dates to the Upper Pala Eolithic in Europe, around 30,000 years ago. During this period of human history cereals constituted just one of many food sources exploited by hunting and gathering pal, Eolithic European diets were based mainly on animal proteins and fats. Cereals and bread became a staple food during the Neolithic, around 10,000 years ago, when wheat and barley were among the first plants to be domesticated in the Fertile Crescent. Wheat-based agriculture spread from Southwest Asia to Europe, North Africa and the Indian Subcontinent. In other parts of the world Cereals such as, rice (East Asia), maize (the Americas) and sorghum (sub-Saharan Africa) are also sometimes made into bread, were independently domesticated and formed the basis of alternative agricultural systems. Around the world, the shift from varied hunter-gatherer subsistence to agricultural diets based predominantly on a cereal staple such as wheat bread marked an important turning point in human history. Though in many ways nutritionally deficient compared to hunting and gathering, cereal crops allowed agricultural societies to sustain much larger populations than had previously been possible, which in turn led to greater economic specialization, social complexity and eventually the rise of civilized states. (Adeyemi, I.A. and M.A. Idowu, 1990)

The development of leavened bread can also probably be traced to prehistoric times. Yeast spores occur everywhere, including the surface of cereal grains, so any dough left to rest will become naturally leavened. Although leavening is likely of prehistoric origin, the earliest archaeological evidence is from ancient Egypt. Scanning electron microscopy has detected yeast cells in some ancient Egyptian loaves. However, ancient Egyptian bread was made from emmer wheat and has a dense crumb. In cases where yeast cells are not visible, it is difficult, by visual examination, to determine whether the bread was leavened. As a result, the extent to which bread was leavened in ancient Egypt remains uncertain.

The importance of bread in the formation of early human societies cannot be overstated. From the western half of Asia, where wheat was domesticated, cultivation spread north and west, to Europe and North Africa, and enabled humans to become farmers rather than hunters and foragers. This in turn led to the formation of towns, as opposed to the nomadic lifestyle, and gave rise to more and more sophisticated forms of societal organization. Similar developments occurred in eastern Asia, centered on rice, and in the Americas with maize. (Tannahill, Reay, 1973) 


\section{2 History of Composite Flour}

In the1960 and 1970 composite flour survey very often found themselves at the focus of attention in European and other international research cereal research. Most of the studies in this field were supported by FAO (food and Agriculture Association of the United Nations).In these two decades bread consumption increased continually in the mainly of the Developing countries. There were three main reasons for this

- Growing population

- Changing eating habits

- Overall increase income

In most of cases wheat flour needed for making breads and other bakery products had to be imported due to bread can only be made from imported moderately gluten wheat which is not suitable for cultivation in the tropical areas for climatic reasons (Edema et al., 2005).In developing countries the import wheat had an adverse effect on the balance of trade. For this reasons FAO and developing countries were interested in the possibility of replacing wheat needed bake products with flour obtain form the home grown products. Possible sources were tuberous, Cereals such as Rice, Maze. (ICC.reports on 9 symposium on composite flours 1976 -2000)

Although it is well known that no other crop can be achieved the baking property of Wheat (Triticum aestivum). This is the major food produce among all the cereal crops. It is a staple food of large segment of world population. Wheat is extensively used for production of flat breads such as the steam-leavened chapatti, a major source of nutrients and staple diet common to Pakistan, India, and some parts of Africa. (Kadam et al., Food Processing Technology 2012)

Legumes have been known as "a poor man's meat". They supply protein, complex carbohydrates, fibre and essential vitamins and minerals to the diet, which are low in fat and sodium and contain no cholesterol. Legumes have been identified as low glycaemic index food. A low glycaemic index food are very important in the dietary treatment of diabetes mellitus, increases satiety, facilitate the control of food intake and has other health benefits for healthy subject in terms of post-prandial glucose and lipid metabolism . Regular consumption of pulses may have important protective effects on risk for cardiovascular disease. Due to social reasons, the Indian peoples heavily depend on pulses a source of proteins, vitamins and minerals in the daily diet. Chick pea, pigeon pea, mung bean, urad bean, lentil and field pea are the importance pulses of significant dietary importance.In addition to nutritional importance, they are also being recognized as having therapeutic and medicinal properties. Chickpea occupies first position among pulses representing 35\% of total cultivated area of pulses and contributing $45 \%$ of total production in India. In Madhya Pradesh chickpea is grown in an area of 2.56 million hector with an annual production of 2.37 million tons. Addition of legume and beans to cereal based products could be a good option for increasing the intake of legumes and beans. In addition, legume proteins are rich in lysine and deficient in sulphur containing amino acids, whereas cereal proteins are deficient in lysine, but have adequate amounts of sulphur amino acids. Therefore, the combination of grain with legume proteins would provide better overall essential amino acid balance, helping to overcome the world protein calorie malnutrition problem. Use of composite flour based on wheat and other cereals including minor 
millets in bakery products is becoming popular because of the economic and nutritional advantages. (Pakistan Journal of Food Sciences, Volume 20, 2010))

The composite flours containing wheat and legumes are being utilized in many parts of the world. The basic composite flour technology refers to the process of mixing wheat flour with cereals and legumes to produce high quality food products in an economical way. Several studies about the influence of the addition of legume flours on the functional properties of bread dough and final bread quality have been reported in the last 30 years. Among the legumes tested, it is worth mentioning the addition of chickpea flour, germinated chickpea flour to wheat flour for obtaining bread. Even though the good results obtained with bread, those studies have not been extended to other cereal baked products. Hence the present work was planned with the objective to develop missi roti /chapatti from composite flour made from wheat, chickpea, soy flour and dried leafy vegetables. Nutritional characteristics, sensory quality and shelf life of the flour and products were studied. According to the scientific investigation, fortification of wheat and corn flour with legumes flour is imposed the nutritional quality in the composite flour (Jeffers et al...1978)

Bread is an important staple food in both developed and developing countries. Wheat (Triticum aestivum) flour of both hard and soft wheat classes has been the major ingredient of leavened bread for many years because of its functional proteins. In Sudan, the consumption of wheat bread is increasing in both rural and urban areas as a consequence of changing taste, convenience and consumer subsidies. However, bread can only be made from imported high gluten wheat which is not suitable for cultivation in the tropical areas for climatic reasons (Edema et al., 2005).Several developing countries have encouraged the initiation of programs to evaluate the feasibility of alternative locally available flours as a substitute for wheat flour. Many efforts have been carried out to promote the use of composite flours, in which portion of wheat flour is replaced by locally grown crops, to be used in bread, thereby decreasing the cost associated with imported wheat (Olaoye et al., 2006). Most of the research conducted on the use of composite flour for bread making purposes (Adeyemi and Idowu, 1990; Dhingra and Jood, 2004; Hsu et al., 2004; Khalil et al., 2000; McWatter et al., 2004) was devoted to studying the effects of different flour substitutions on bread making quality. Acceptability studies conducted at the Food Research Centre in Khartoum, Sudan, indicated that breads made with composite flour of $70 \%$ wheat and $30 \%$ sorghum were acceptable (FAO, 1995). Consumer acceptance trials in Nigeria indicated that breads made with $30 \%$ sorghum flour were comparable to 100\% wheat bread (Aluko and Olugbemi, 1989; Olatunji et al., 1989).

Bread with 30\% sorghum and 70\% wheat was alsoprepared in Senegal (FAO, 1995). Carson and Sun (2000) investigated the rheological properties and bread baking potential of sorghum-based composite flour containing variable amount of vital wheat gluten. They observed a decrease in water absorption, dough strength and extensibility, and increase in mixing time as the sorghum flour proportion was increased in the samples at fixed gluten protein levels. Sorghum is the staple food crop in Sudan where it is consumed in fermented forms, mainly as Kisra (local thin bread), aceda (thick porridge) and nasha (thin porridge).Several studies have indicated the possibility of incorporating sorghum both as whole and decorticated grain in wheat flour at various levels to produce bread when wheat is in short supply. The objective of this study was to evaluate the 
physical and baking properties of whole and decorticated sorghum-wheat composite flours as well as to determine the organoleptic acceptability of the resulting breads. (Tannahill, Reay, 1973).

\subsection{Wheat Flour}

Wheat is a type of grass grown all over the world for its highly nutritious and useful grain. It is one of the top three most produced crops in the world, along with corn and rice. Wheat has been cultivated for over 10,000 years and probably originates in the Fertile Crescent, along with other staple crops. A wide range of products are made from it by humans, including most famously flour, which is made from the grain itself.

Today, wheat is a grass that grows between 2 and 4 feet ( 0.6 to 1.2 meters) tall. The physical appearance of the grain is familiar to most consumers, with a long stalk that terminates in a tightly formed cluster of plump kernels enclosed by a beard of bristly spikes. The plant is an annual, which means that at the end of each year, fields must be plowed and prepared again to grow the grass.

Grain from the store is taken to a mill where it is used to make different types of flour. White flour is made from the endosperm only. Whole meal flour uses all parts of the grain. Brown flour contains about $85 \%$ of the original grain, but some bran and germ have been removed. Find out more about how flour is made here. If you buy flour and use it at home, keep it on a cool, dry, airy shelf in its bag, or in a clean, dry container. White flour will keep for 6 to 9 months, wholemeal or brown flour for 2 to 3 months. A wheat grain is a seed. This means it is designed for reproducing. Each grain of wheat is made up of three distinct parts. First there is the coarse outer bran layer. Inside the bran layer the grain is made up of two main parts. The smaller part is called the germ. The larger part is called the endosperm. The pericarp (part of the outer bran layer) is a tough skin which protects the inner seed from attack. The inner seed coats control the intake of water by the seed. The germ is the embryo plant. It has a radicle which can grow into a root system and a plumule which can develop into the stems, leaves and ears of a new wheat plant. The endosperm is the starchy store of food, which the germ will feed on while it is growing.

Atta is the flour used to make most South Asian flatbreads, such as; chapati, roti, naan and puri. Most Atta is milled from the semi-hard wheat varieties, also known as durum wheat, which comprises $90 \%$ of the Indian wheat crop, and is more precisely called durum Atta.( Food-india.com)

Hard wheat have a high content of gluten (a protein composite that gives elasticity), so dough made out of Atta flour are strong and can be rolled out very thin. Indian wheat are mostly Durum wheat, which are high in protein but less in "bread forming gluten" so the bread when baked with this flour does not rise as well and tend to be dense. Atta 1 was listed as having $17.5 \%$ protein content. It is very finely ground and is almost completely pale cream in colour, with tiny specks of slightly darker bits which is bran. (http://www.thekitchn.com/how-to-make-softer-and-fluffie Accessed on 27.10.2013)) 